\title{
Responsible biology, aging populations and the 50th anniversary of the "War on Cancer"
}

\author{
Colin Farrelly
}

Received: 29 March 2021 / Accepted: 24 May 2021 / Published online: 4 June 2021

(C) The Author(s), under exclusive licence to Springer Nature B.V. 2021

\begin{abstract}
The 50th Anniversary of the National Cancer Act of 1971 is the opportune time to critically reflect on the determinates of what the philosopher of science Philip Kitcher calls "responsible biology". Responsible biology entails that scientists have an obligation to reflect on the ends, and not just the means, of scientific research and to conceive of themselves as artisans working for the public good. Taking stock of the successes and limits of the half a century "war on cancer" reveals the importance of attending to the most significant risk factor for cancer and other chronic diseases- aging itself. The case is made for considering the biology of aging, and the aspiration to slow the rate of biological aging, as critical components of responsible biology in an aging world. As growing numbers of humans survive into late life, the primacy the goal of disease elimination occupies within biomedical research must be revised, and greater effort should be directed towards the goal of increasing the human healthspan and delaying and compressing disease, frailty and disability in late life.
\end{abstract}

Keywords Aging · Biogerontology · Cancer · Infectious disease $\cdot$ Lifespan versus healthspan . Responsible biology

C. Farrelly $(\bowtie)$

Queen's University, Kingston, ON K7L 3N6, Canada

e-mail: farrelly@queensu.ca

\section{Introduction}

Scientific reasoning is... at all levels an interaction between two episodes of thought - a dialogue between two voices, the one imaginative and the other critical; a dialogue, if you like, between the possible and the actual, between proposal and disposal, conjecture and criticism, between what might be true and what is in fact the case. ${ }^{1}$

The year 2021 marks the 50th anniversary of the National Cancer Act of 1971. In his state of the union address, President Richard Nixon asked for an appropriation of an extra $\$ 100$ million to launch an intensive campaign to find a cure for cancer. In 2008 the National Cancer Institute renewed this same aspiration when it set the Challenge Goal to eliminate the suffering and death due to cancer by 2015. And in 2016 the 21st Century Cures Act (Cures Act) was signed into law, the purpose of which is to "accelerate the discovery, development, and delivery of twentyfirst century cures, and for other purposes" (Public Law 114-255).

Half a century since President Nixon's original launch of the "war on cancer" and unfortunately there has not been a single cure for any of the $200+$ types of cancer that cause mortality in humans. Today cancer still is, as it was half a century ago, the second leading cause of death in the United States. The 50th

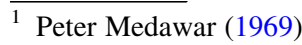


Anniversary of The National Cancer Act is the opportune time to reflect on how the heavily funded half-a-century US national campaign to conquer cancer matches up with the demands of what the philosopher of science Philip Kitcher (2004) has called "responsible biology".

Kitcher argues that responsible conduct in science extends beyond obvious professional ethics like dealing honestly with colleagues, not misreporting lab results, etc.; it also applies to critically scrutinizing the underlying intellectual suppositions of scientific research itself (e.g. what the appropriate "ends" of basic science are) and science policy decision-making (e.g. the investment and allocation of research funds). More specifically, Kitcher argues that the following three theses are an integral part of what he calls "responsible biology":

(1) Scientists have an obligation, individually and collectively, to reflect on the ends-not just on the means-of scientific research.

(2) scientists should conceive of themselves as artisans working for the public good, whose efforts are directed toward an ideal of wellordered science; and

(3) this ideal of well-ordered science should be understood in a global and democratic fashion (Kitcher 2004).

This essay examines the details of what is entailed by responsible biology, as this ideal pertains to biomedical research in a world of aging populations. Since the rise of epidemiology in the nineteenth century, the primary "ends" of biomedical research, for both public health and clinical medicine, have been the elimination of specific diseases (through both prevention and treatment). In the early twentieth century in the United States this end was successfully applied to a wide variety of infectious diseases that were responsible for early-life mortality. But in the late twentieth century the focus on mitigating the proximate causation of pathology had been expanded to include targeting chronic diseases like cancer. The question this article is concerned with is as follows: Does responsible biology sanction the continued fixation on disease control in today's aging world? The answer advanced-after considering (1) the successes and limitations of the past half a century of the war on cancer in the United States, as well as (2) findings from the biology of aging (biogerontology) concerning the limits on human longevity and the malleability of the inborn aging process- is "No". Rather than continue to prioritize the goal of extending life via disease elimination for populations reaching the upper limits of human lifespan, the more important goal of public health, medicine, biotechnology, and the health sciences should now shift toward delaying and compressing the period of the lifespan when frailty and disability increase substantially (Olshansky 2018).

\section{Two Strategies to Promote Human Longevity}

The argument advanced in this essay is based on scientific insights that pre-date President Nixon's "war on cancer" in 1971. Writing in The New Scientist in 1969, the gerontologist and Head of UCL's MRC's Group of Ageing Alex Comfort proposed a radically different approach to human longevity than the strategy of disease elimination. The latter dominated the biomedical sciences for the past half a century after the developed countries mitigated the most serious early-life mortality risks from infectious diseases like small pox, typhoid fever, malaria, polio, diphtheria, dysentery, etc. Comfort describes the two approaches to human longevity as follows:

Science can be expected to affect human longevity favourably in two quite distinct ways. It already does so by suppressing causes of premature death, through the repertoire of applications which now render our lives less nasty, brutish and short than they would otherwise be. It could also affect longevity by postponing the process which causes our liability to disease and death to increase logarithmically with time. The first of these two influences already means that in privileged countries more and more people reach the so-called "specific age" (75 80 years), but it has not altered that age appreciably. The second, which is now in the stage of active research, would aim at postponement or slowing of ageing itself. (Comfort 1969)

The war on cancer has been at the forefront of the campaign to suppress premature death via disease elimination. And while real success has been made in terms of reducing cancer mortality, the longer people live, the more important aging biology becomes as a 
primary risk factor in determining both length and quality of life (Olshansky 2018). As Comfort had already observed more than 50 years ago, there is a a biological"wall" against further human life-prolongation which cannot be shifted very far by further improvements in medicine or living conditions (Comfort 1969). A critical reflection on the successes and limits of the half a century campaign to conquer cancer in the US reveals how sage Comfort's predictions were. Thus the primary goal for biomedical research today should not be preoccupied with increasing longevity per se, but rather with increasing the human healthspan. That is, the period of time humans can enjoy healthy living by delaying and compressing the disease, frailty and disability of late life.

Following Comfort (1969) and many other biogerontologists (e.g. Neugarten and Havighurst 1977; Holliday 1999; Butler et al. 2008; Rae et al. 2010; Kennedy et al. 2014; Crimmins 2015; Kaeberlein et al. 2015; Olshansky 2018), this opinion essay makes the case that responsible biology in an aging world must strive to improve the quality of life for older people (i.e. increasing the healthspan) vs preventing death by helping older populations survive by managing multi-morbidity. Responsible biology today requires the concern for rate control (of the aging process) to replace the prominence currently enjoyed by disease control in the biomedical sciences. In the conclusion it is suggested that the tragedy of the recent COVID-19 pandemic is a vivid illustration of the consequences of the multi-decade campaign to prevent premature deaths via disease elimination vs attending to increasing the human healthspan. The Centers for Disease Control and Prevention (2020a, b, c) estimates that $80 \%$ of the deaths that have involved COVID-19 have occurred among persons age 65 and older and thus some have argued that COVID-19 is an emergent disease of aging (Santesmasses et al. 2020).

\section{The Origins of Responsible Biology: The Battle Against Infectious Disease}

Before President Nixon declared a war on cancer in the early 1970s, the United States had already waged a successful, multi-decade campaign against infectious disease. And it was both the success, and general strategy employed, in the campaign against infectious disease that lead to the same goal (i.e. disease elimination) and means (identifying and mitigating the proximate causation of pathology) being adopted to try (with much less success) to conquer the chronic diseases of late life.

In the early twentieth century the goal of disease elimination helped reduce early-life mortality by significantly reducing the threats from different viruses and bacteria. Contaminated food, milk and water could cause many serious infections, ranging from polio and typhoid fever to botulism and Salmonella. By identifying the proximate causation of infectious disease, health innovations like the sanitation revolution, pasteurization, food inspection and immunizations helped dramatically reduce earlylife mortality in the twentieth century.

In the year 1900 life expectancy at birth in the United States (for all races, both sexes) was age 47.3 (CDC 2010). In the 50 years from 1900 to 1950 US life expectancy at birth had risen from 47.3 to age 68.2 (a $44.2 \%$ increase). Nearly all the mortality decline in the first half of the twentieth century is accounted for by reductions in infectious disease, which today is only a small share of total mortality (Cutler and Miller 2005). The determinates of responsible biology are provisional; that is, they are subject to change as a result of alterations in the health challenges facing human populations and new empirical insights and discoveries concerning the most effective strategies for preventing and treating disease, frailty and disability. The primary health need of the US population in the early twentieth century was the need to combat infectious disease and prevent early-life mortality. And a dedication to public health measures meant that, by the middle of the twentieth century, the United States was close to realizing that end as life expectancy had risen by over $44 \%$ in just half a century, from age 47.3 to 68.2 .

Success in mitigating the proximate causation of infectious diseases was then extended to other health challenges, such as to automobile and workplace safety, and to the chronic diseases of late life. But unlike reducing the threats to early-life mortality, which can confer decades of additional health to the persons saved from polio, malaria, smallpox and tuberculosis, adding more health by eliminating the chronic conditions more prevalent in late life (like cancer, heart disease, stroke, Alzheimer's etc.) is impeded by the limits of the human lifespan. 
The $44.2 \%$ increase in life expectancy from 1900 to 1950 dwarfs the $11.3 \%$ increase from 1970 (age 70.8 years) to just before the COVID-19 pandemic in 2019 (age 78.8) (CDC 2020b). The presumption of the war on cancer, and the disease elimination paradigm of the biomedical sciences more generally, was that the strategy deployed to combat the infectious diseases responsible for early-life mortality should be applied in the same way to combat the chronic diseases that are most prevalent in late life, like cancer.

\section{Years of the War on Cancer}

The National Cancer Institute (2020) estimates that approximately 606,520 Americans died of cancer in 2020, and the associated costs of cancer care is estimated to have risen $27 \%$ from 124.57 billion to 157.77 billion 2010 US dollars from 2010 to 2020 (Mariotto et al. 2011). Even with the COVID-19 pandemic, the chronic diseases of late life like cancer continue to be the most prevalent diseases and cause of death in the United States. And like the pandemic, chronic diseases such as cancer have significant economic costs. Economic models using the human capital approach estimated the annual productivity cost from cancer mortality to be approximately $\$ 115.8$ billion in the year 2000; and the projected value was $\$ 147.6$ billion for 2020 (Bradley et al. 2008). And the NIH Report (2020) investment in cancer research was $\$ 7.1$ billion. Despite the magnitude of the problem of cancer today, the last half a century has witnessed a significant improvement in our understanding of cancer, an understanding that has translated into new preventative measures, diagnostics and improved cancer treatments.

Over the past half a century, the focus on the proximate causation of cancer has revealed many modifiable risk factors, such as smoking and obesity. However both remain significant public health challenges today. Despite decades of promoting smoking cessation public health campaigns, the CDC estimates that smoking accounts for more than 480,000 deaths every year, with about 15 of every 100 adult men $(15.3 \%)$ and nearly 13 of every 100 adult women still smoking (CDC 2020c). And obesity, defined in adults as a body mass index $(\mathrm{BMI}) \geq 30$, is associated with higher incidence of a number of cancers (LaubySecretan et al. 2016) and has become increasingly prevalent over the past three decades. The prevalence of obesity doubled between the 1976-1980 and the 1999-2000 National Health and Nutrition Examination Surveys. And between 1999 and 2000 through 2017-2018 the prevalence of obesity increased from 30.5 to $42.4 \%$ (and the prevalence of severe obesity increased from 4.7 to $9.2 \%$ ) (CDC 2020d). The CDC's NCHS Data Brief "Prevalence of Obesity and Severe Obesity Among Adults: United States, 2017-2018" estimates that the age-adjusted prevalence of obesity in adults is $42.4 \%$ (CDC 2021).

Over the past 50 years passive modes of transportation like driving (vs walking) to work have become more popular (Hoehner et al. 2012), the nature of work has become more sedentary and less physically demanding, and inactive leisure activities beyond watching television have expanded with the advent of the internet in the 1990s and, more recently, social media use (which can start as early as infancy (Trinh et al. 2019)). Prolonged periods of sitting can have adverse health outcomes (Owen et al. 2009). Approximately $80 \%$ of US adults and adolescents are insufficiently active, based on the Physical Activity Guidelines for Americans (Piercy et al. 2018). And the COVID-19 pandemic has exacerbated this problem, leading to a decline in daily step count (Tison et al. 2020). This is a significantly worrying trend as evidence suggests that higher levels of physical activity are associated with lower cancer incidence (Rezende et al. 2008; Keimling et al. 2014; McTiernan et al. 2019; Patel et al. 2019).

The preventative measures for combating cancer have been a mixed story of success and failure. The same is true of cancer diagnostics and treatments. While no cancer has been cured in the past half a century war on cancer, an early diagnosis can significantly alter the prognosis when it comes to cancer mortality. For colorectal cancer, for example, screening measures like colonoscopy and stool tests can help detect abnormal colon growths (even before they are cancerous). Skin cancer is the most commonly diagnosed type of cancer in the US and early screening can be a life saving intervention. The 5-year relative survival rate for melanoma is $93 \%$, ranging from $99 \%$ for cases diagnosed at a localized stage to $27 \%$ for distant-stage (American Cancer Society 2021).

But there have also been challenges with screening for cancer. There are the problems of false negatives and false positives, which can result in delayed 
treatment or unnecessary further testing and procedures that may be harmful. And there can be harms from cancer screening, including complications from biopsies and subsequent treatment, as well as the risk of overdiagnosis and overtreatment.

Cancer treatments have improved significantly since the early 1970s. Endocrine therapies such as tamoxifen have revolutionized the treatment of breast cancer, resulting in significant decreases in cancerrelated mortality (Tremont et al. 2017). In the 1980s Breast-Conserving Surgery was also utilized, a surgical option that provided an acceptable oncological outcome but also diminished the psychological burden, offered better cosmetic results, and reduced postoperative complications (Rahman 2011). Chemotherapy, surgery and radiotherapy are the most common types of cancer treatments available today.

While the annual death toll from cancer in the US exceeds half a million people per year, there are an estimated 16.9 million individuals with a history of cancer that were alive on January 1, 2019 (American Cancer Society 2019). That number is a testament to the progress in cancer treatment. Cancer treatments have saved lives. But at the same time it is important to acknowledge the reality that the standard cancer treatments all have potential adverse side-effects, sometimes severe effects. Chemotherapy has adverse side effects because it works on active cells. These include the cancer cells, but also potentially healthy cells in the mouth, digestive system, blood and hair follicles. Radiation therapy is a common treatment option for cancer, but early and late side effects limit radiation dose and might affect the long-term healthrelated quality of life of the patient (Bentzen 2006).

\section{Well-Ordered Science in an Aging World}

Kitcher's account of "well-ordered science" stipulates that the inquiries science pursues must be in accordance with the agenda that would have been set by a group of discussants that meet the following ideal requirements:

(1) They are fully informed of the scientific opportunities,

(2) They are fully informed of one another's needs, and
(3) They are dedicated to doing the best they can to accommodate the needs of all. (Kitcher 2001)

The primary health needs of the US population in the early twentieth century was the need to combat infectious disease and prevent the early-life mortality it often caused. By the middle of the twentieth century that need was beginning to be realized. As such, two novel needs began to emerge as early-life mortality was abated: (1) the need to continue to suppress causes of premature death that are more prevalent in later life (like cancer) AND (2) the need to promote health in late life ("adding life to years vs simply years to life").

The fixation on tackling the proximate causation of diseases like cancer lead to the prioritization of (1), but responsible biology mandates that (2) be just as much (if not more of) a priority because attaining (1) without (2) brings about the unsettling predicament that is now manifest in the United States. Despite unprecedented amounts of investment in biomedical research, US life expectancy has (as Comfort predicted in 1969) plateaued, and even declined. Between 1959 and 2016, US life expectancy increased from 69.9 years to 78.9 years but declined for 3 consecutive years after 2014 due to midlife mortality increases across all racial groups, caused by drug overdoses, alcohol abuse, suicides, and a diverse list of organ system diseases (Woolf and Schoomaker 2019). And the increase in life expectancy between 2017 and 2018 for the total population was only 0.1 year, of which approximately $30.2 \%$ of the positive contribution can be attributed to decreases in cancer mortality (CDC 2020e). The COVID-19 pandemic is estimated to have reduced US life expectancy in 2020 by 1.13 years (Andrasfay and Goldman 2021).

Decades of research dedicated to prioritizing the goal of preventing premature death has now run into the predicament of the biological limit to the average (as well as maximum) lifespan. Based on hypothetical reductions in mortality rates, Olshansky, Carnes and Cassel (1990) estimated the upper limits to human longevity, concluding that life expectancy at birth would not exceed 85 years. And the age at death of the world's oldest person- Jeanne Calment at age 122- has not increased since the 1990s (Dong, Milholland and Vijg 2016). To continue to prioritize the goal of preventing premature death for a population reaching the limits of average lifespan has resulted in extending the period of time older persons can survive while 
managing multi-morbidity, but it has not increased the healthspan nor compressed disease and disability in late life. Thus the continued war on specific diseases like cancer is very costly in terms of the healthcare expenditures needed to reduce late-life mortality, and it has left older populations vulnerable to new health risks, such as the COVID-19 pandemic.

The biomedical sciences have focused, disproportionately, on only one way of increasing human longevity- pursuing the goal of disease elimination by identifying and targeting the proximate causation of pathology. This proved very sage when applied to combating the infectious diseases responsible for early-life mortality. But if has proved much less successful when applied to the complex, chronic diseases of late life, like cancer. There have certainly been demonstrable successes over the past 50 years of the war on cancer, such as the identification of the cancer risks of smoking and obesity, and genetic mutations which can increase the risks of certain types of cancer, and improved diagnostics and treatments. But as The American Cancer Society (2020) notes, as many as $20 \%$ of people who die from lung cancer every year have never smoked or used any other form of tobacco and that lung cancer in people who have never smoked is one of the most fatal cancers. And Tindle et al. (2018) found that four of ten lung cancers occurred in former smokers with more than 15 years since quitting.

Progress against cancer is constrained by the reality that the populations most at risk of cancer mortality are older persons, and thus many cancer survivors are still at high risk of disease, frailty and disability. Eliminating the risk of prostate cancer, for example, does not reduce the risks of every other type of cancer older persons are at risk of, such as lung, liver or breast cancer. The same is also true for the other prevalent diseases of late life, like cardiovascular disease, osteoporosis, type 2 diabetes, hypertension or Alzheimer's disease. Furthermore, as Olshansky notes, finding a cure for one of the late onset diseases like cancer can mean that more debilitating diseases can become more prevalent:

The hazard in old age is not so much that one disease displaces another but that the new diseases are often much more debilitating. For example, finding a cure for cancer may cause an unintended increase in the prevalence of Alzheimer disease. (Olshansky 2018)

When reflecting on the limitations of the fixation on the proximate causation of cancer, Mel Greaves comments:

The lifetime risk of a clinical cancer diagnosis in humans is around one in three. Each year more than 10 million cases are diagnosed.

...Overall, these data suggest that cancer risk is underpinned by intrinsic fallibility, and that risk increases with increasing age and is greatly exacerbated by some aspects of human activity. ....Any engineer confronted with a recurring fault in a complex machine or plant would look not only at the immediate source and cause of the fault, but at system design, its compromises and limitations. The engineer will resort to a blueprint; we have evolutionary biology.

The essential tenet of the new discipline of evolutionary or Darwinian medicine is that susceptibility to malfunction and disease must in part reflect historical or evolutionary legacies. The corollary is that we might then benefit from stepping back to take a broader look at human history and our protracted evolutionary trajectory. (Greaves 2007)

The field of scientific research known as "biogerontology" (or "geroscience") adopts this broader look at human history, as it seeks to understand why we age and why aging makes us more susceptible not only to cancer, but to other chronic diseases, frailty and disability in late life.

\section{Targeting the Aging Process}

Many scholars from different disciplines (e.g. kinesiology, sociology, gerontology and biology) study aging and thus "aging" itself is somewhat of a contested concept in that different scholars often refer to different things when they refer to aging. The scientists that study the biology of aging function with something like the following, specific, understanding of what biological aging is: the progressive loss of function accompanied by decreasing fertility and increasing mortality with advancing age (Kirkwood and Austad 2000). Children, for example, are 
developing, but not biologically aging. The reduction or elimination of infectious disease risks that cause high rates of early-life mortality thus improve the probability of children surviving into adulthood, at which time they will begin to senesce. The vast majority of persons saved from early-life mortality can enjoy decades of healthy life as a result of a reduction of the extrinsic health risks of infectious disease.

However adults already in late life (age $>70$ ), who develop one particular type of cancer, have already survived decades with an exponential rise in their mortality risk. Eliminating the specific cancer they have developed does not, unfortunately, reduce their risks of developing other types of cancer or chronic conditions. Nearly 200 years ago the British actuary Benjamin Gompertz made the important observation that there is a law of progression describing the exponential rise in death rates between sexual maturity and old age (Gompertz 1825; Olshansky and Carnes 1997; Kirkwood 2015; Ledberg 2020). Saving persons of advanced age from cancer mortality obviously yields diminished health dividends compared to the benefits reaped in the early twentieth century by reducing the mortality risks of early-life. This does not mean it is not possible to increase the human healthspan, only that focusing on the proximate causation of pathology is a much more limited strategy to prioritize in a world of aging populations.

The probability of developing (all sites) cancer within the first 5 decades from birth to age 49 is only 1 in 29, but this rises to 1 in 3 by age 70 (Siegel et al. 2021). Why does our risk of cancer and other chronic diseases increase as we age? To answer this question the evolutionary (or ultimate) causation of disease must be examined which is the focus of the field of study known as biogerontology.

A dominant account of the evolution of aging is known as the disposable soma theory (Kirkwood 1977; Kirkwood and Holliday 1979), which posits that the winning evolutionary strategy for sexually reproducing species- species that have had to find ways to survive the extrinsic risks of the hostile environments of life on this planet- is to prioritize health during the "essential lifespan". The "essential lifespan" of a species is defined as the time required to fulfill the Darwinian purpose of life, that is, successful reproduction and continuation of generations (Rattan 2000). Bruce Carnes (2007) usefully describes the disposable soma account of aging as follows: The world is a dangerous place. Death is, for all living things on this planet, inevitable. In order for any species' existence to persist over time a solution to death must be found. And that solution, for us and for other sexually reproducing species, is reproduction. There is thus a real race between reproduction and death, and all the species alive today are, at least for the moment, winning this race. But for all the species that are now extinct, like the Mammoth and Neanderthal, the race was lost.

The upshot of the disposable soma account of aging is that aging is the product of evolutionary neglect. Rather than focusing so intensely on the goal of eliminating each specific disease of aging, responsible biology should also aspire to redress the evolutionary neglect which limits the opportunities for health in late life (especially as populations age). This is what Comfort (1969) had proposed over half a century ago when he argued that the priority should be to improve the quality of life for older people vs increasing the lifespan of the human species by suppressing causes of premature death.

Comfort argued for this conclusion based on the following three points:

1. Longer vigorous adult life can probably not be achieved in any other way.

2. The project appears on present evidence to be feasible.

3. Most important, it ought to be easier to affect a rate than to rewrite a programme. Accordingly, if we want to postpone death, it should be very much easier to postpone cancer or atheroma than to prevent or cure these conditions when established. (Comfort 1969)

Half a century of the "war on cancer" and the other diseases in late life show Comfort was correct about his first point. US life expectancy has not continued to increase despite enormous investments in biomedical research expenditures as well as significant scientific advances like the sequencing of the human genome. This is the outcome one would expect if Comfort was correct when he predicted that there is a biological "wall" against further human life-prolongation which cannot be shifted very far by further improvements in medicine or living conditions (Comfort 1969).

Comfort's second point, that the prospects of altering human aging appear feasible, has been shown to be a defensible (though still unproven) hypothesis. 
For nearly a century, experiments in rats and mice showed that aging was malleable. Research in the 1930's (McCay et al. 1935) showed that rats and mice that are given about 40 percent less food than they would eat on their own live about 40 percent longer than do fully fed controls (Miller 2002). Caloric restriction in rodents delays many of the chronic conditions associated with aging and thus can be considered an "anti-aging" intervention. There is debate about whether these anti-aging effects are due to caloric restriction or dietary restriction (Solon-Biet et al. 2014) and how far the evidence in animal studies can be extrapolated to humans (Demetrius 2005; Le Bourg and Redman 2018).

Caloric restriction induces stress response pathways in organisms, and while it is too burdensome an intervention to be pursed as a gerontological intervention for human populations, the prospect of developing a drug that retards the aging process might be a viable way to safely and effectively retard aging, thus reducing not only the risks of cancer, but many of the other risks of disease, frailty and disability in late life.

Over the past decade a number of potential molecules have been identified as have anti-aging properties. Metformin, for example, has been safely utilized as a pharmacological intervention to help control type 2 diabetes for decades. In experiments on animals, metformin has been shown to slow aging (Novelle et al. 2016). And now researchers are hoping a similar effect can be shown in humans. Because of its low cost and proven safety over many decades, metformin is among one of the top candidates for a likely first generation of applied gerontological interventions. TAME (Targeting Aging with Meformin) (Barzilai et al. 2016) is a clinical trial to test the drug metformin as a safe and effective intervention against several age-related diseases. Some believe that a fertile source for therapies slowing aging is FDA approved drugs whose safety has been investigated (Snell et al. 2018).

Rapamycin is a drug that was developed from soil on Easter Island and is currently used as a drug to help prevent the rejection of transplanted organs for patients undergoing organ transplant. Recent experiments have found that consuming rapamycin can extend lifespan, including in mammals. In a study of mice (Harrison et al. 2009) that were already 600 days old (which is roughly equivalent to a 60 year-old human) before being fed rapamycin, this intervention increased the median and maximal lifespan of both male and female mice. The initial study concludes that rapamycin may extend lifespan by postponing death from cancer, by retarding mechanisms of aging, or both. Since this initial report in 2009, there have been fourteen additional studies showing that rapamycin increased the lifespans of male and female mice and these studies on mouse data demonstrate that this molecule is effective in preventing, even reversing, a broad rage of age-related conditions and thus warrants being described as an "anti-aging" intervention (Selvarani et al. 2020).

Comfort's third point- that it is easier to prevent disease via rate control than treat and cure diseases after they are manifest- is one that the next half of century of biomedical research will hopefully reveal to be true if greater efforts are invested in making age retardation a reality of preventative medicine. But what is true at this stage is that 50 years of a "war on cancer" has not eliminated cancer. Cancer prevention through slowing the aging process would have the added benefits of delaying the onset of other agerelated conditions and compressing the period of time humans experience frailty and disability in late life.

\section{Conclusion}

In 1969 Alex Comfort made the following three predictions:

1. That direct experiment on the delaying of ageing in Man is virtually certain to be in hand somewhere by 1975 , using battery techniques, and probably at more than one centre.

2. That if by good luck one of the currently fancied rodent techniques proves directly applicable, some agent colorably reducing the rate of human ageing is likely to be known within 15 years. (It would not be fully proven until most of the untreated controls had aged.)

3. That the increase from such a technique could be as much as 20 per cent, possibly more, and would be worth while if it were less. (There is, of course, a staircase effect here-the greater the success, the greater the further investment, from which the beneficiaries might in turn live to benefit: this is quite unforeseeable.) (Comfort 1969) 
These predictions did not come to fruition, at least not on the timescale Comfort had expected. Biogerontology remained a relatively marginal field of scientific research through the 1970 s to the early 2000s. The bulk of research funding continued to be targeted towards research on specific diseases like cancer. And the design of human clinical trials to test the efficacy and safety of drugs, required to be granted approval from the Food and Drug Administration, have been designed around the paradigm of disease prevention, management and treatment.

An applied gerontological intervention would bring to fruition the vision of the biomedical sciences Comfort endorsed back in 1969. Because aging is a major risk factor for many chronic conditions, not just cancer but also heart disease, Alzheimer's, etc., an aging intervention would be the ultimate form of preventative medicine. Comfort was correct in his assertion that evidence available in the 1960's indicated that there is a clock or clocks, and that by tampering with this mechanism the timing of degenerative changes could be altered, not just piecemeal, but across the board.

Biogerontology is an integral part of responsible biology for today's aging populations. The chronic diseases of late life are not just a threat to the health of the populations living in rich, developed countries. Low and middle income countries (like China) have among the world's largest aging populations. Globally, there were 703 million persons aged 65 or over in 2019 (United Nations 2020). The significance of keeping aging populations healthy is even more vital in countries where older persons cannot rely on advanced healthcare systems or extensive state pensions. Healthy aging is a concern of economic development, as well as a concern for preventing disease, frailty and disability. And finally, achieving healthy population aging can also help redress gender inequality as it is typically daughters that are expected, in most cultures, to contribute more to the care of older parents.

Responsible biology prescribes that scientists conceive of themselves as artisans working for the public good, whose efforts are directed toward an ideal of well-ordered science. This ideal needs to transcend the limitations of the disease elimination paradigm of the biomedical sciences. If the aspiration to alter the rate of biological aging becomes a reality it would be among the most significant public health advancement of the twenty-first century, potentially offering more health to the estimated 2 billion people alive by the year 2050 who will be over age 60 (World Health Organization 2018).

The upheaval of the COVID-19 pandemic of 2020-2021 has revealed the fragilities of the decades-long disease-elimination approach to human longevity. Infectious diseases are typically more lethal for developing countries than developed countries, as the latter can rely on more advanced, well-funded healthcare systems to reduce infectious disease mortality for their populations. So when the developed countries- like the US, the UK, Italy and Spainreported significantly higher COVID-19 mortality per 100,000 people than poorer countries in the continent of Africa, for example, researchers were puzzled (Maeda and Nkengasong 2021). Given Africa's weaker health systems, and the fact that the continent also faces significant challenges with other infectious diseases such as HIV and malaria, one would expect the developed countries to fare much better with respect to COVID-19 mortality than developing countries in Africa. But that does not appear to be the case. And for biogerontologists one major explanatory factor stands out as an obvious explanation for this- the median age of a population determines its mortality risk to COVID-19 because age is the biggest risk factor for death. Africa has a comparatively young population, with a median population age of 19.7 years for the continent versus 38.6 years for the United States (Moustapha, Bertrand and Simon 2020). The developed world's success in postponing death towards the upper limits of the human lifespan has left their aged populations vulnerable to COVID19 mortality, a disease which can be described as an "emergent disease of aging" (Santesmasses et al. 2020). One of the most important lessons to be learned from this recent pandemic is the need to therapeutically address degenerative aging processes to prevent aging-related ill health as a whole (Barzilai et al. 2020; Farrelly 2021).

An important part of the story of a population's vulnerability to infectious (and chronic) disease is the story of our evolved biology. The half a century campaign to eliminate cancer has not prioritized the study of our evolved biology and how aging leaves us susceptible to multi-morbidity, frailty and disability in late life. The goal of disease elimination, and the strategy of prioritizing the identification and 
mitigation of the proximate causation of pathology, have extended life expectancy but not the human healthspan. To promote the health of today's aging populations the next half a century of responsible biology must heed Comfort's call to improve the quality of life for older people. Attempts to develop preventive measures against individual conditions related to aging have been, for the most part, frustrating and unsuccessful (Butler et al. 2008). By successfully modulating the most significant risk factor for most chronic diseases, an applied gerontological intervention would yield a much more significant health dividend for today's aging population than a cure for a specific disease of late life.

\section{References}

American Cancer Society (2019) Cancer treatment \& survivorship facts \& figures 2019-2021. American Cancer Society, Atlanta

American Cancer Society (2020) Lung cancer risks for nonsmokers. https://www.cancer.org/latest-news/why-lungcancer-strikes-nonsmokers.html. Accessed 24 Feb 2021

American Cancer Society (2021) Survival rates for melanoma skin cancer. https://www.cancer.org/cancer/melanomaskin-cancer/detection-diagnosis-staging/survival-ratesfor-melanoma-skin-cancer-by-stage.html. Accessed 24 Feb 2021

Andrasfay T, Goldman N (2021) Reductions in 2020 US life expectancy due to COVID-19 and the disproportionate impact on the Black and Latino populations. Proc Natl Acad Sci USA 118(5):2014746118

Barzilai N, Crandall JP, Kritchevsky SB, Espeland MA (2016) Metformin as a tool to target aging. Cell Metab 23(6):1060-1065

Bentzen SM (2006) Preventing or reducing late side effects of radiation therapy: radiobiology meets molecular pathology. Nat Rev Cancer 6(9):702-713

Bradley CJ, Yabroff KR, Dahman B, Feuer EJ, Mariotto A, Brown ML (2008) Productivity costs of cancer mortality in the United States: 2000-2020. J Natl Cancer Inst 100(24): 1763-1770

Butler RN, Miller RA, Perry D, Carnes BA, Williams TF, Cassel C, Brody J, Bernard MA, Partridge L, Kirkwood T, Martin GM, Olshansky SJ (2008) New model of health promotion and disease prevention for the $21 \mathrm{st}$ century. BMJ 337(7662): 149-150

Carnes B (2007) Senescence as viewed through the lens of comparative biology. Ann N Y Acad Sci 1114:14-22

Centers for Disease Control and Prevention (2010) Table 22: Life expectancy at birth, at 65 years of age, and at 75 years of age, by race and sex: United States, selected years 1900-2007. https://www.cdc.gov/nchs/data/hus/2010/022. pdf. Accessed 24 Feb 2021
Centers for Disease Control and Prevention (2020a) Older adults. https://www.cdc.gov/coronavirus/2019-ncov/needextra-precautions/older-adults.html. Accessed 15 May, 2021

Centers for Disease Control and Prevention (2020b) Mortality in the United States. https://www.cdc.gov/nchs/products/ databriefs/db395.htm. Accessed 24 Feb 2021

Centers for Disease Control and Prevention (2020c) Current cigarette smoking among adults in the United States. https://www.cdc.gov/tobacco/data_statistics/fact_sheets/ adult_data/cig_smoking/index.htm. Accessed 24 Feb 2021

Centers for Disease Control and Prevention (2020d) Prevalence of obesity and severe obesity among adults: United States, 2017-2018. https://www.cdc.gov/nchs/products/ databriefs/db360.htm. Accessed 24 Feb 2021

Centers for Disease Control and Prevention (2020e) Changes in Life Expectancy at Birth, 2010-18. https://www.cdc.gov/ nchs/data/hestat/life-expectancy/life-expectancy-2018. htm. Accessed 24 Feb 2021

Centers for Disease Control and Prevention (2021) Adult obesity facts. https://www.cdc.gov/obesity/data/adult.html. Accessed $24 \mathrm{Feb} 2021$

Comfort A (1969) Longer life by 1990? New Scientist 11:549-551

Crimmins EM (2015) Lifespan and healthspan: past, present, and promise. Gerontologist 55(6):901-911

Cutler D, Miller G (2005) The role of public health improvements in health advances: the twentieth-century United States. Demography 42(1):1-22

Demetrius L (2005) Of mice and men. When it comes to studying ageing and the means to slow it down, mice are not just small humans. EMBO Rep 6:S39-44

Dong X, Milholland B, Vijg J (2016) Evidence for a limit to human lifespan. Nature 538(7624):257-259

Farrelly C (2021) The COVID-19 pandemic, biogerontology and the ageing of humanity. J Gerontol Ser A. https://doi. org/10.1093/gerona/glab027

Gompertz B (1825) On the nature of the function expressive of the law of human mortality, and on a new mode of determining the value of life contingencies. Philos Trans R Soc Lond B Biol Sci 115:513-583

Greaves M (2007) Darwinian medicine: a case for cancer. Nat Rev Cancer 7(3):213-221

Harrison DE, Strong R, Sharp ZD, Nelson JF, Astle CM, Flurkey K, Nadon NL, Wilkinson JE, Frenkel K, Carter CS, Pahor M, Javors MA, Fernandez E, Miller RA (2009) Rapamycin fed late in life extends lifespan in genetically heterogeneous mice. Nature 460(7253):392-395

Hoehner CM, Barlow CE, Allen P, Schootman M (2012) Commuting distance, cardiorespiratory fitness, and metabolic risk. Am J Prevent Med 42(6):571-578

Holliday R (1999) Ageing in the 21st century. Lancet 354: SIV4.

Kaeberlein M, Rabinovitch PS, Martin GM (2015) Healthy ageing: the ultimate preventative medicine. Science 350(6265):1191-1193

Kennedy BK, Berger SL, Brunet A, Campisi J, Cuervo AM, Epel ES, Franceschi C, Lithgow GJ, Morimoto RI, Pessin JE, Rando TA, Richardson A, Schadt EE, Wyss-Coray T, Sierra F (2014) Geroscience: linking ageing to chronic disease. Cell 159(4):709-713 
Keimling M, Behrens G, Schmid D, Jochem C, Leitzmann MF (2014) The association between physical activity and bladder cancer: systematic review and meta-analysis. Br J Cancer 110(7):1862-1870

Kirkwood TBL (1977) Evolution of aging. Nature 270:301-304

Kirkwood TBL (2015) Deciphering death: a commentary on Gompertz (1825) On the nature of the function expressive of the law of human mortality, and on a new mode of determining the value of life contingencies. Philos Trans R Soc Lond B Biol Sci 370(1666):20140379

Kirkwood TBL, Austad S (2000) Why do we age? Nature 408(9):233-238

Kirkwood TBL, Holliday R (1979) The evolution of ageing and longevity. Philos Trans R Soc Lond B Biol Sci 205:531-546

Kitcher P (2001) Science, truth and democracy. Oxford University Press, New York

Kitcher P (2004) Responsible biology. Bioscience 54(4):331-336

Lauby-Secretan B, Scoccianti C, Loomis D, Grosse Y, Bianchini F, Straif K (2016) International agency for research on cancer handbook working group. Body fatness and cancer-viewpoint of the IARC Working group. N Engl J Med 375(8):794-798

Le Bourg E, Redman LM (2018) Do-It-Yourself calorie restriction: the risks of simplistically translating findings in animal models to humans. Bioessays 40(9):e1800087

Ledberg A (2020) Exponential increase in mortality with age is a generic property of a simple model system of damage accumulation and death. PLoS ONE 15(6):e0233384

Maeda J, Nkengasong J (2021) The puzzle of the COVID-19 pandemic in Africa. Science 371(6524):27-28

Mariotto AB, Yabroff KR, Shao Y, Feuer EJ, Brown ML (2011) Projections of the cost of cancer care in the United States: 2010-2020. J Natl Cancer Inst 103(2):117-128

McCay CM, Cromwell MF, Maynard LA (1935) The effect of retarded growth upon the length of life span and upon the ultimate body size. J Nutr 10(1):63-79

McTiernan A, Friedenreich CM, Katzmarzyk PT, Powell KE, Macko R, Buchner D, Pescatello LS, Bloodgood B, Tennant B, Vaux-Bjerke A, George SM, Troiano RP, Piercy KL, 2018 Physical activity guidelines advisory committee (2019) Physical activity in cancer prevention and survival: a systematic review. Med Sci Sports Exerc 51(6):1252-1261

Medawar P (1969) Science and literature. Perspect Biol Med 12(4):529-546

Miller R (2002) Extending life: scientific prospects and political obstacles. Milbank Q 80(1):155-174

Moustapha M, Bertrand L, Simon PJ (2020) COVID-19 in Africa: dampening the storm? Science 369(6504):624-626

National Cancer Institute (2020) Cancer Statistics https://www. cancer.gov/about-cancer/understanding/statistics. Accessed 24 Feb 2021

Neugarten B, Havighurst R (1977) Extending the human life span: social policy and social ethics. National Science Foundation, Washington

NIH Report (2020) Estimates of funding for various research, condition, and disease categories (RCDC). https://report. nih.gov/funding/categorical-spending\#. Accessed 24 Feb 2021
Novelle MG, Ali A, Diéguez C, Bernier M, de Cabo R (2016) Metformin: a hopeful promise in aging research. Cold Spring Harbor Perspectives in Med 6(3):25932

Olshansky SJ (2018) From lifespan to healthspan. J Am Med Assoc 320(13):1323-1324

Olshansky SJ, Carnes BA (1997) Ever since Gompertz. Demography 34(1):1-15

Olshansky SJ, Carnes BA, Cassel C (1990) In search of Methuselah: estimating the upper limits to human longevity. Science 250(4981):634-640

Owen N, Bauman A, Brown W (2009) Too much sitting: a novel and important predictor of chronic disease risk? Br J Sports Med 43(2):81-83

Patel AV, Friedenreich CM, Moore SC, Hayes SC, Silver JK, Campbell KL, Winters-Stone K, Gerber LH, George SM, Fulton JE, Denlinger C, Morris GS, Hue T, Schmitz KH, Matthews CE (2019) American College of Sports Medicine Roundtable Report on physical activity, sedentary behavior, and cancer prevention and control. Med Sci Sports Exerc 51(11):2391-2402

Piercy KL, Troiano RP, Ballard RM, Carlson SA, Fulton JE, Galuska DA, George SM, Olson RD (2018) The physical activity guidelines for Americans. J Am Med Assoc 320(19):2020-2028

Public Law 114-255, 130 STAT. 1033 (2011) To accelerate the discovery, development, and delivery of 21 st century cures, and for other purposes. Enacted: December 13, 2016. https://www.congress.gov/114/plaws/publ255/ PLAW-114publ255.pdf. Accessed 24 Feb 2021

Rae MJ, Butler RN, Campisi J, de Grey AD, Finch CE, Gough M, Martin GM, Vijg J, Perrott KM, Logan BJ (2010) The demographic and biomedical case for late-life interventions in ageing. Sci Transl Med 2(40):40 cm21

Rahman GA (2011) Breast conserving therapy: a surgical technique where little can mean more. J Surg Tech Case Rep 3(1):1-4

Rattan S (2000) Biogerontology: the next step. Ann N Y Acad Sci 908(1):282-290

Rezende LFM, Sá TH, Markozannes G, Rey-López JP, Lee IM, Tsilidis KK, Ioannidis JPA, Eluf-Neto J (2018) Physical activity and cancer: an umbrella review of the literature including 22 major anatomical sites and 770000 cancer cases. Br J Sports Med 52(13):826-833

Santesmasses D, Castro JP, Zenin AA, Shindyapina AV, Gerashchenko MV, Zhang B, Kerepesi C, Yim SH, Fedichev PO, Gladyshev VN (2020) COVID-19 is an emergent disease of aging. Aging Cell 19(10):e13230s

Selvarani R, Mohammed S, Richardson A (2020) Effect of rapamycin on aging and age-related diseases-past and future. Geroscience. 10:2. https://doi.org/10.1007/s11357020-00274-1

Siegel RL, Miller KD, Fuchs HE, Jemal A (2021) Cancer statistics. A Cancer J Clin 71(1):7-33

Snell TW, Johnston RK, Matthews AB, Zhou H, Gao M, Skolnick J (2018) Repurposed FDA-approved drugs targeting genes influencing aging can extend lifespan and healthspan in rotifers. Biogerontology 19(2):145-157

Solon-Biet SM, McMahon AC, Ballard JW, Ruohonen K, Wu LE, Cogger VC, Warren A, Huang X, Pichaud N, Melvin RG, Gokarn R, Khalil M, Turner N, Cooney GJ, Sinclair DA, Raubenheimer D, Le Couteur DG, Simpson SJ (2014) 
The ratio of macronutrients, not caloric intake, dictates cardiometabolic health, aging, and longevity in ad libitumfed mice. Cell Metab. 19(3):418-430

Tindle HA, Duncan MS, Greevy RA, Vasan RS, Kundu S, Massion PP, Freiberg MS (2018) Lifetime smoking history and risk of lung cancer: results from the Framingham heart study. J Natl Cancer Inst 110(11):1201-1207

Tison GH, Avram R, Kuhar P, Abreau S, Marcus GM, Pletcher MJ, Olgin JE (2020) Worldwide effect of COVID-19 on physical activity: a descriptive study. Ann Intern Med 173(9):767-770

Tremont A, Lu J, Cole JT (2017) Endocrine therapy for early breast cancer: updated review. Ochsner J 17(4):405-411

Trinh MH, Sundaram R, Robinson SL, Lin TC, Bell EM, Ghassabian A, Yeung EH (2019) Association of trajectory and covariates of children's screen media time. JAMA Pediatr 174(1):71-78
United Nations (2020) International Day of Older PersonsHomepage. https://www.un.org/development/desa/ageing/ international-day-of-older-persons-homepage.html. Accessed 24 Feb 2021.

Woolf SH, Schoomaker H (2019) Life expectancy and mortality rates in the United States, 1959-2017. J Am Med Assoc 322(20):1996-2016

World Health Organization (2018) Ageing and Health. https:// www.who.int/news-room/fact-sheets/detail/ageing-andhealth. Accessed 24 Feb 2021.

Publisher's Note Springer Nature remains neutral with regard to jurisdictional claims in published maps and institutional affiliations. 